eISSN: 2172-9077

https://doi.org/10.14201/fjc2019184152

\title{
PANORAMA DE MUJERES DOCUMENTALISTAS ÁRABES
}

\section{Overview of arab women filmmakers of documentaries}

\author{
Dra. Carolina BRACCO \\ Universidad de Buenos Aires, Argentina \\ carobracco@gmail.com \\ (iD) ORCID
}

Fecha de recepción del artículo: 30/03/2019

Fecha de aceptación definitiva: 20/04/2019

\begin{abstract}
RESUMEN
El artículo presenta un panorama general de las realizadoras de cine documental en el mundo árabe. Partiendo de una introducción que analiza los aspectos relevantes en relación a la situación de las mujeres, su participación en el espacio público y su ingreso en la producción audiovisual se adentra luego en el análisis de sus principales referentes dividiendo la región en tres grandes segmentos. El primero de ellos aborda la descripción del cine egipcio, pionero en la región, así como la participación femenina en sus comienzos y en la producción documental. El segundo se centra en el Sham (Siria, Líbano y Palestina) analizando la particularidad de una región atravesada por los conflictos interétnicos y la tragedia palestina. El tercero desarrolla la producción audiovisual documental de las mujeres del Magreb (Argelia, Marruecos y Túnez) en relación con las identidades culturales múltiples que se ven plasmadas en sus obras.
\end{abstract}

Palabras clave: cine; documental; mujeres; árabe; identidad; género.

\begin{abstract}
This paper provides a general overview of women documentary filmmakers in the Arab world. The text intends to elaborate on these aspects in relation to the condition of women's roles, their participation in the public sphere and their participation in audiovisual production. Subsequently, it focuses on the analysis of the most remarkable figures, dividing the region in three segments. The first segment approaches the Egyptian cinema, a pioneer in the region. Likewise, in this segment, women's participation in the Egyptian cinema in its beginning and their participation in the documentary production are addressed. The second segment focuses on the Sham (Syria, Lebanon and Palestine) analyzing the particular characteristics of a region which has gone through several interethnic conflicts and the Palestinian tragedy. The third segment elaborates on the documentary audiovisual production of women filmmakers from the Maghreb (Algeria, Morocco and Tunisia) in relation with their multiple cultural identities which are in turn reflected on their productions.
\end{abstract}

Key words: cinema; documentary; women; arab; identity; gender. 


\section{INTRODUCCIÓN}

Con la notable excepción de Egipto, la mayoría de los países árabes comenzaron su producción audiovisual luego de lograr la independencia de las potencias europeas a mediados del siglo XX. Debido a ello, la cinematografía de la región está íntimamente ligada a la construcción de los discursos nacionalistas que primaron en la construcción de los Estados poscoloniales.

En lo que respecta a la elaboración de documentales, y específicamente a la producción femenina, ésta se encuentra relacionada a dos cuestiones ligadas entre sí. La primera tiene que ver con el estatus de las mujeres y su avance o retroceso en la adquisición de derechos y participación en la vida pública. La segunda, relativa a las circunstancias que fueron atravesando los incipientes Estados-nación y las políticas de promoción y/o censura que incentivaron.

A lo largo del presente artículo presento un mapeo de la región que intenta dar cuenta de estas tres cuestiones relacionadas: el estatus femenino, el desarrollo del cine documental y el uso del dispositivo por parte de las mujeres. Dado que se trata de una región sumamente diversa e imposible de abordar en su totalidad en un trabajo de estas características, mi intención es exponer una presentación general de los principales aspectos de estos tres factores y su interrelación.

Para ello, expongo un análisis dividido en tres secciones que acompañan la presente introducción. La sección 2 despliega los principales aspectos del desarrollo de la industria cinematográfica egipcia, pionera en la región, cuya historia excede con creces al resto. La sección 3 aborda la presentación de los tres países que se aglutinan dentro del Sham -Siria, Líbano y Palestina- cuya historia se encuentra íntimamente relacionada entre sí. La sección 4 se ocupa de los tres países del Magreb -Argelia, Marruecos y Túnez- unidos por una historia colonial semejante aunque con grandes diferencias en lo relativo al status de las mujeres. Por último, se esbozan los comentarios finales con la expectativa de que este panorama impulse nuevas investigaciones que profundicen sobre los aspectos que aquí puedo poco más que mencionar.

Así, este estudio se presenta como una aproximación basada principalmente en mi experiencia como investigadora y programadora de cine documental árabe realizado por mujeres complementado con la revisión bibliográfica citada en cada caso para la referencia del/la lector/a. La selección de los países se hizo tomando en cuenta aquellos que poseían algún tipo de participación femenina en la producción audiovisual documental. Asimismo, a partir del relevamiento de datos y de conversaciones con directoras de la región, se desarrolló un listado de las pioneras de cada país mencionado. Teniendo en cuenta que la participación femenina en el cine documental -a pesar de ir en crecimiento- es relativamente reciente, el período estudiado se concentra desde comienzos de los años 70 hasta la actualidad.

En el resto de esta sección desarrollo los lineamientos generales sobre el estatus de las mujeres en el mundo árabe en el contexto de las independencias y los debates que ha habido en torno a ello, a modo de presentación general de la cuestión.

De manera general, las medidas tomadas por los Estados poscoloniales para intervenir en la vida de los ciudadanos y ciudadanas se plasmaron en la legislación familiar. Ésta, sumada al desarrollo de los programas educativos y otras medidas de control social no favorecieron la emancipación femenina sino que degradaron la posición social de la mujer. Según Kandiyoti (1991), ello se dio básicamente por dos razones. La primera relativa a que las medidas para la emancipación femenina no coinciden 
necesariamente con el impulso democratizador y la creación de una sociedad civil en la que sus intereses se vean representados. Por el contrario, esta labor fue llevada adelante por gobiernos autoritarios que buscaron controlar o tutelar esos intereses. Los mismos dirigentes que garantizaban nuevos derechos para las mujeres eran los que proscribían asociaciones y organizaciones autónomas allí donde existían.

En segundo término, los controles comunales sobre las mujeres continuaron creciendo y en algunos casos se intensificaron. Ello sucedió en contextos plagados de contradicciones (Abu Lughod, 1998). La penetración del modo de producción capitalista llevó en muchos casos al desmembramiento de las comunidades, el ensanchamiento de la brecha entre clases sociales y el debilitamiento de la solidaridad familiar. Con las masivas migraciones del campo a las urbes, la red de protección/control hacia las mujeres se amplió y las tradicionales relaciones de autoridad de hombres hacia ellas -y entre las mayores a las jóvenes- se extendieron. Además, el fracaso en la repartición igualitaria de recursos creó redes clientelares de privilegio en el acceso al empleo o al crédito. Ello estancó la movilidad social, lo cual agravó las tensiones existentes entre clases y clivajes.

Las estructuras estatales construidas a partir de las independencias tuvieron el foco puesto en la posición social de las mujeres y su participación en el espacio público (Joseph, 1991). Durante el período colonial, el ámbito doméstico-familiar -de "las mujeres y los niños»- había permanecido como una fortaleza ante la avanzada en los asuntos "públicos" de las potencias foráneas que controlaban la región: Francia e Inglaterra. Concluida la era colonial, en cada uno de los países se desarrolló un proceso de socialización que supuso la obediencia de la familia al Estado a través de la legislación familiar expresada en los Códigos de Estatus Personal basados en la jurisprudencia islámica (Ruiz de Almodóvar, 2005).

En este contexto, la "cuestión de la mujer» surgió como un terreno de disputa ideológica que simbolizaba las aspiraciones progresistas de la élite secularista o el anhelo de autenticidad cultural en términos de la tradición islámica. La centralidad de la imagen femenina como símbolo de identidad es desde entonces la plataforma sobre la que se disputan las contiendas ideológicas hasta nuestros días, donde aún se resiente desde algunos sectores cualquier manifestación feminista como parte de una política cultural imperial. Quizás por ello ninguna de las directoras mencionadas en este estudio se identifica como "feminista", e incluso algunas de ellas rechazan de plano esta categoría, a pesar de que en su abrumadora mayoría trabajan temas relativos a los derechos de las mujeres, así como cuestiones tocantes al patrimonio cultural, los niños y niñas y las consecuencias de los conflictos armados.

Las mujeres árabes ingresaron masivamente en el género documental en los años 70 en el contexto de los manifiestos de cine del Tercer Mundo de Solanas y Getino y la posguerra de 1967 (Van de Peer, 2017, p. 4). Este conflicto armado fue un punto de inflexión en la historia árabe moderna. Si bien su finalidad era recuperar la Palestina histórica, la derrota militar supuso no sólo la pérdida del resto del territorio palestino, sino también de porciones de Líbano, Siria y Egipto. Ello tuvo un fuerte impacto en la región. Por un lado, demostró lo falible del sueño panárabe liderado por el presidente egipcio Gamal Abdel Nasser. Por el otro, dio nacimiento a la organización armada palestina, dispersada en la región tras la pérdida de su patria en 1948 a manos de las milicias sionistas. Estos dos factores fueron determinantes -ya sea por influencia o por reacción- en el desarrollo del cine militante documental de fines de los años 60. 
En 1968 el Colectivo del Nuevo Cine Árabe (NCA) publicó su propio manifiesto en el Festival de Cine de Damasco (Siria) buscando con ello sacudir las bases del cine local, dominado por los melodramas y los backstage musicals egipcios (Samak, 1977). El manifiesto llamaba al compromiso político y social con la realidad y los problemas que aquejaban a los pueblos árabes, aunque sin poner especial foco en la posición degradada de la mujer en estas sociedades. Sin embargo, el contexto y las facilidades técnicas -de equipos y presupuesto- que presentaba el documental hizo de él un género asequible para las mujeres. Su incorporación en la década posterior brindó una mirada propia de su experiencia y su lectura sobre la realidad femenina en esos países.

\section{EL CINE EGIPCIO Y SUS PIONERAS}

A comienzos del siglo XX, El Cairo era el epicentro cultural de la región y en 1917 ya contaba con 80 salas de proyección (Thoraval, 1988, p. 8). Con una impronta marcada por el interés y el capital extranjero, el cine egipcio se desarrolló rápidamente repitiendo fórmulas europeas y hollywoodenses a las que daba un tinte local. En 1927 se produjo la primera película realizada por un equipo completamente local: Layla. La película inició el género de "aventuras de beduinos» caracterizado por reproducir la imagen de un Oriente folclórico centrado en la rivalidad entre dos civilizaciones. Layla fue producida y protagonizada por una de las pioneras del cine egipcio: Aziza Amir. Dos años después otra destacada figura femenina, Asia Daguir, produjo y protagonizó un film con un argumento similar bajo el nombre Belleza del desierto. Su sobrina Mary Queeny también se dedicó a la actuación y producción y junto a su marido Ahmad Galal creó una de las primeras compañías cinematográfica del país, Gala Films. Con diversa suerte, otras figuras como Bahiga Hafez y Badia Masabni ingresaron en el mundo del cine en esta época, donde las mujeres jugaban un rol fundamental en el ambiente artístico tanto sobre los escenarios como en la producción de espectáculos (Bracco, 2017).

Con este auspicioso comienzo, el cine egipcio en los años 30 ya se consagraba como el corazón de la industria cultural de masas de la región y sus películas eran distribuidas en todo el mundo arabófono. En 1949, tres años antes de la independencia, se promulgó la primera ley de censura que prohibía cualquier representación de una imagen degradada del país como huelgas y manifestaciones, campesinos pobres, carros tirados por burros y, en general, lo que denominaba como «costumbres orientales» (Shafik, 1988, p. 132). A pesar de las rígidas reglamentaciones, que con diferentes orientaciones perduran hasta el día de hoy, el cine realista tuvo grandes exponentes en el país como Salah Abu Seif, Tawfiq Saleh y Shadi Abdel Salam.

Con el impulso trasnacional del Tercer Cine y el local del NCA surgió un nuevo interés en retratar e interpretar la realidad social a través del género documental. La primera egipcia en llevar adelante esta tarea fue Ateyah al Abnoudy. Su primer corto documental, Caballo de barro, fue realizado en 1971 y tiene un estilo que ella llama «realismo poético» (Hillauer, 2005, p. 15). Relata en una entrevista:

Veo la vida de manera poética. Amo vivir y pensar que la gente pobre en mi país hace lo posible para trabajar y crear vida. Intento transmitir este amor por la vida en todas mis películas, incluso si la gente vive en condiciones muy difíciles. Los trato con mucho respeto. Me encanta ver sus caras en la pantalla. Vengo de la clase trabajadora, pero el 
cine es de la clase media, por eso tengo que ser fuerte en mantener la relación con mi clase. Si no, estaría perdida (Ibídem, p. 46).

Caballo de barro ganó más de 30 premios internacionales y los años siguientes Al Abnoudy filmó cerca de un corto documental anualmente hasta 2004. Su cine es caracterizado como "directo" ya que sus films privilegian los primeros planos y la intención de no intervenir en el accionar de los participantes. En el año 1996 dirigió su largometraje documental de mayor popularidad, Dias de democracia, donde pone el foco en las mujeres de clase baja y rurales de Egipto. Sin considerarse feminista ni querer ser etiquetada como "cineasta mujer", sus películas han tratado sobre todo de los problemas de las egipcias.

Entre las pioneras del cine documental junto con Abnoudy se destaca por su trayectoria Nabiha Lotfy. Ambas fundaron la Asociación de Cineastas Egipcias en 1990 para apoyar la producción de sus colegas. Nabiha Lotfy, originaria de Sidón (Líbano) se trasladó a El Cairo a fines de los años 50 y estudió en el Instituto Nacional de Cine con profesores como Youssef Chahine, con quien mantuvo una gran amistad hasta la muerte de este en 2008. Chahine le contagió el amor por el cine pero fue con Shadi Abdel Salam -sobre quien, al momento de la muerte de ella en 2015 estaba realizando su último film- que Nabiha Lotfy adquirió la práctica que le dio las herramientas para realizar en 1977 su primera película. Porque las raíces nunca mueren, retrata la vida y la lucha de las mujeres en el campamento de refugiados palestinos Tal al Zaatar.

A lo largo de su carrera Nabiha Lotfy realizó películas relacionadas con la temática de "las mujeres y los niños" que incluye la serie Habla la mujer árabe (1994), Juegos de niños (1990), Mujeres (2000). El último de sus documentales, sobre la vida de la artista Tahia Carioca, fue realizado en 2010. Sin duda su trayectoria y su generosidad inspiró a muchas mujeres a transitar el camino del cine documental incluyendo a su hermana menor, Arab Lotfy quien dirigió en 1993 El espejo de Jamila, un homenaje a las militantes palestinas de los años 60 y 70 haciendo referencia a la más famosa y destacada luchadora argelina, inspiración de muchas de ellas: Jamila Bouheirad. Acompañada por las hermanas Lotfy, Amal Ramses comenzó su carrera como directora de cine tras abandonar su profesión de abogada y recibir una beca en Madrid para estudiar dirección. Hermana del también director Basel Ramses, realizador de Columpios (2007), Amal dirigió su primer documental en 2005, Sólo sueños, en el que un grupo de mujeres hablan de sus sueños y aspiraciones. En 2008 esta directora egipcia fundó la Caravana de Cineastas Árabes y Latinoamericanas que conectó ambas regiones en un proyecto pionero. Más tarde amplió el espectro y dio nacimiento al Festival Internacional de Mujeres de El Cairo, que aún se desarrolla anualmente en esa ciudad, único en la región.

Desde sus inicios, el cine documental ha estado dominado por mujeres en Egipto, un género en el que continúan creando una forma de comunicarse y mostrar el patrimonio histórico, cultural y arquitectónico de su pueblo, así como aspectos de la cultura popular. Esta coyuntura, desde Caballo de barro hasta las realizaciones más recientes ha generado el rechazo y la censura por parte de los organismos oficiales, que, desde comienzos de siglo, están obsesionados con no proyectar una mala imagen del país. Mostrar la pobreza, los derechos negados, es de alguna forma comprometerse con ellos. 


\section{La región del Sham: Siria, Líbano y Palestina}

La historia contemporánea del Sham ha estado fuertemente influida por la creación del Estado de Israel en 1948. Ello afectó lógicamente a los palestinos, que se vieron desposeídos de su territorio y dispersados en terceros países, pero también cambió para siempre la demografía y los destinos políticos de esas recién creadas naciones árabes. Sumado a ello, las divisiones políticas que delimitaron las potencias europeas tras la Primera Guerra Mundial y el desmembramiento del Imperio Otomano generaron divisiones y enfrentamientos entre grupos étnicos y religiosos. En una región marcada a fuego por las masacres y la intolerancia, las expectativas por el futuro, expresadas en las representaciones de la niñez, y la exaltación de los orígenes y la identidad cultural, manifiestos en las representaciones de las mujeres, son una constante en la filmografía local.

La historia del cine palestino comienza con la de su revolución nacida en los campamentos de refugiados en el sur de Líbano. La revolución se expandió como un proyecto político y cultural por toda la región a partir de 1965. En el momento más álgido de la expansión trasnacional por la lucha anticolonial, este movimiento fue inspiración y vanguardia política, social y cultural. A partir de 1968 el cine revolucionario se sumó para difundir y fortalecer la causa nacional entre la diáspora y entre los pueblos del mundo; posters, poesía, fotografía y cine transmitieron y propagaron la narrativa revolucionaria. El cine documental que se desarrolló hasta fines de la década del 60 en los campamentos de refugiados fue financiado por las facciones políticas palestinas y promovieron sus intereses. Se caracterizaba por lo que Muhammad Hamza Ghanayem (200, p. 17) denomina "ideología de refugiado»: la idea de que el presente es temporal y no hay lugar para la memoria. Los palestinos estaban unidos por un trauma nacional, un presente de lucha y un destino de retorno.

La idea de conectar pasado, presente y futuro queda plasmada en el manifiesto del grupo dirigido por Mustafa Abu Ali en 1973 donde se describen sus objetivos: «revelar la situación del pueblo palestino y describir las etapas de la lucha palestina y árabe hasta la liberación nacional» (Hennebelle y Khayati, 1977). Sulafa Jadallah y Khadiga Habashneh, miembros de este grupo, fueron las primeras directoras. Además de formar parte de la cooperativa dirigida por Abu Ali, Khadiga dirigió dos películas: Niños, aunque... (1981) y Mujeres por Palestina (1982). Instituyó un archivo para preservar las películas y secuencias del Instituto de Cine de la Organización por la Liberación de Palestina (OLP) así como las películas sobre Palestina hechas por otras organizaciones; de la UNRWA (Agencia de la ONU para los refugiados), televisión internacional, y películas extranjeras:

El espíritu rebelde que caracterizaba nuestras actividades estaba también presente en la cinemateca que establecimos, que presentaba películas de grupos de liberación similares de todo el mundo: Cuba, Vietnam, estábamos en contacto con creativos de otros lugares que veían a la cámara como un arma en las manos de la revolución y la lucha del pueblo y estábamos en la búsqueda de un nuevo lenguaje (Habashneh en Sela, 2018).

Tras la invasión israelí a Líbano en 1982 se desconoció el paradero del acervo. La incansable búsqueda de este patrimonio cultural palestino es retratada por Azza El Hassan en Reyes y extras (2004) donde esta directora sigue las pistas de las cintas. En 2018 Rona Sela, de la Universidad de Tel Aviv, reveló el destino de los archivos en su film Saqueados y escondidos, estrenado el 15 de mayo de ese año, cuando se 
cumplieron 70 años de la creación del Estado de Israel y la tragedia palestina. También en 1982 las masacres en los campamentos de refugiados de Sabra y Shatila, perpetradas por las milicias cristianas libanesas en connivencia con el ejército israelí, inspiraron a una de las documentalistas fundamentales de la siguiente década: Mai Masri. Sus tres primeras películas Bajo los escombros (1983), Flores salvajes: Las mujeres del sur de Líbano (1986) y La generación de la guerra (1989) las realizó junto a su marido, Jean Chamoun en Líbano. El registro que se hacía de la vida de los refugiados tras la partida de la OLP en 1982, cuenta Masri (2008), era documentado por periodistas extranjeros de los que los refugiados desconfiaban espionaje.

A partir de la década siguiente dirigió la trilogía Niños de fuego (1990), Niños de Shatila (1998) y Fronteras de sueños y miedos (2001), entre otras. En estas películas Masri mantiene el foco en la niñez y el futuro, pero creando un lenguaje cinematográfico propio, intimista, que va del relato personal al comunitario a la vez que juega con los límites entre documental y ficción con una estética poética. En 2015 estrenó su primer film de ficción, 3000 noches, inspirado en sus documentales anteriores. En el film relata la historia de Layali (nombre que significa «noches»), una maestra palestina que es condenada a prisión por las fuerzas de ocupación israelíes. Layali debe luchar por mantener la esperanza y transitar su embarazo y maternidad en terribles circunstancias.

Entre las libanesas, Heiny Srour emprendió la filmación del documental La hora de la liberación ha llegado... jFuera el colonialismo! (1974), seleccionada por la Semana de la Crítica en el Festival de Cannes en junio ese mismo año. El documental llevó dos años de preparación en los que la directora y su equipo registraron la lucha revolucionaria del pueblo de Zofar (Omán) contra el imperialismo inglés y fue la primera película filmada en un país árabe no mediterráneo. Las conversaciones fueron registradas en el dialecto local con un foco especial en el rol de las mujeres en la lucha revolucionaria.

En los primeros años 70, antes de la guerra civil (1975-1990), Beirut fue el centro de la intelectualidad y del librepensamiento para todos los árabes que huían de la represión y censura en sus países. Egipto, tras la firma de los acuerdos de paz con Israel y el cambio de rumbo iniciado luego de la muerte de Nasser y la asunción de Anwar el Sadat, ya no era el referente del socialismo árabe, y mucho menos de la lucha anticolonial. En este contexto, y con el fortalecimiento económico que la actividad palestina representaba en el país, se desarrolló un fuerte movimiento por los derechos de las mujeres. Con el estallido de la guerra civil, el escenario cambió drásticamente y muchos libaneses -cineastas o no- utilizaron el cine para documentar los trágicos hechos que transcurrieron a lo largo de esos años. Entre ellos estaba Jocelyne Saab, una periodista educada en París que se convirtió en la más prolífera documentalista del país. Su primera película, Líbano en la tormenta (1975) fue seguida de Niños de la guerra, Beirut nunca más (ambas de 1976), Cartas de Beirut (1979) y Beirut, mi ciudad (1985). Saab hizo uso de su experiencia como reportera de guerra para transmitir en todos estos films la nostalgia por los tiempos de paz y la devastación de una ciudad dividida por los enfrentamientos entre musulmanes (Beirut occidental) y cristianos (Beirut oriental). Con el correr de los años y la intensificación de los enfrentamientos, este trabajo se volvió imposible y comenzó a representar la realidad a través de la ficción: "Hago imágenes. Primero eran imágenes de guerra, y después tuve que empezar a fabricarlas porque ante la destrucción que veían mis ojos ya no podía recoger lo real. Tuve que recrear todo. Y así es como me volqué hacia la ficción» (Saab, 2009 en Mostafa, 2015, p. 38). 
En Siria, el cine documental -contrariamente al de ficción, financiado por el Estado- no se desarrolló como en los dos países anteriormente mencionados. En este contexto destaca Hala al Abdallah, una de las personalidades más significativas del cine árabe. No sólo por su inmensa labor como directora sino por el apoyo que ha brindado a otros realizadores de la región. Su opinión sobre el lugar del cine documental es ilustrativa de la situación del país:

El documental es un medio para expresarse, para gritar, para mostrar la realidad, para tomar trozos de la realidad y ponerlas frente al público, para ir realmente a lo profundo y hacer salir los dolores, las lágrimas, las risas y exponerlas ante el público. Para mí el documental es también hacer salir las palabras ocultas en el interior de cada uno y exponerlas, que puedan ser escuchadas por el público. Todo eso para un pueblo como el sirio es una necesidad vital. No somos conscientes de la necesidad de la fabricación de ese género cinematográfico. No sentimos la necesidad ni la utilidad, hasta qué punto es interesante. Hasta qué punto puede ser interesante y útil para nuestro presente y nuestro futuro. Y todo eso es un resultado de un sistema que siempre ha prohibido la libertad de expresión a los jóvenes. Con la ausencia total de libertad de expresión, para mí esto va directamente en la misma línea con la ausencia total de la realización de documentales (al Abdallah en Forum Transregionale Studien, 2016).

Al Abdallah fue la primera persona en Siria que realizó un largo documental en 2006: Soy la que lleva las flores a su tumba seguido por iNo olvides el comino! (2008). Su trabajo en el exilio, está atravesado por esta traumática experiencia y es de carácter experimental y poético. En el contexto de la "primavera árabe» (2010-2011) rodó Como si estuviéramos cazando una cobra (2012).

\section{La Región del Magreb: Argelia, Marruecos y Túnez}

Los tres países del Magreb comparten una geografía y una historia colonial común. Lejanos al poderío otomano, sufrieron la influencia del poder colonial francés de manera mucho más penetrante que sus vecinos orientales. La ligazón que mantienen con Francia se manifiesta en el hecho de que la mayoría de las cineastas magrebíes fueron formadas en ese país y se expresan en esa lengua a la vez que en sus propios dialectos (darja, amazigh, bereber), por lo que su filiación cultural -sumada a la religiosa y regional- es múltiple.

En su estudio comparativo de los tres países, Charrad (2001) sostiene que las diferencias en el equilibrio de poder entre el Estado nacional y las comunidades con base local durante el período independentista son la causa de las enormes diferencias que se observan en el diferenciado acceso de las mujeres a sus derechos, establecidos en los Códigos de Estatus Personal. Sin lugar a dudas, el tunecino fue -y continúa siendo hasta hoy- el más progresista de la región. Entre otras modificaciones a la legislación anterior, proscribió la poligamia, abolió el repudio en tanto práctica unilateral masculina, estableciendo que el divorcio sólo podía tener lugar en una corte judicial en igualdad de condiciones para hombres y mujeres. Marruecos, por su parte, adaptó la redacción de su Código a las estructuras tradicionales preexistentes, manteniendo las instituciones de la poligamia, el repudio y la ley de herencia como privilegios masculinos. En Argelia, la independencia desencadenó el choque de las tendencias 
reformistas y conservadoras que durante 22 años paralizaron la legislación del Código, en la que la visión de las segundas se impuso.

Si bien se propone como el más liberal de los países magrebíes, Túnez ha ejercido desde su independencia una política de censura restrictiva hacia el mundo audiovisual, lo que decantó en que los cineastas se inclinaran por las ficciones. Si bien la producción cinematográfica comenzó tras la retirada del poder colonial, la participación de las mujeres en la industria no tiene más de tres décadas (Martin, 2011).

La primera película dirigida por una mujer magrebí fue Fatma 75, de la tunecina Selma Baccar. Este documental, realizado en 1975 con el impulso del Año de la Mujeres declarado por las Naciones Unidas, estuvo prohibido en el país por 30 años (Van de Peer, 2017, p. 87). Fatma 75 es un manifiesto feminista, determinado a contradecir la imagen del presidente Bourguiba que se presentaba como el paladín de la liberación femenina. La película traza un recorrido histórico de la lucha de las mujeres en tres etapas: 1930-1938, sobre el surgimiento de la Unión de Mujeres Tunecinas; 1939-1952, sobre la participación de las mujeres durante la lucha por la liberación nacional y 1956-1957, donde relata las complejidades de la redacción del Código y sus implicancias.

Fatma 75 revela las preocupaciones visionarias de Baccar sobre la apropiación de la causa por los derechos de las mujeres, su utilización oficial y las consecuencias que ello tendría para las tunecinas. La elección del nombre es porque así llamaban los franceses a todas las mujeres tunecinas, Fatma es así cualquier mujer tunecina (Ibídem, p. 92). Baccar, como sus colegas de otros países, rehúsa ser llamada feminista y señala que su interés está orientado hacia la psicología de la mujer dentro de la estructura familiar y comunitaria. En palabras de otra cineasta tunecina, Néjia Ben Mabrouk (en Boughédir, 1987): "Baccar siente que los hombres no tienen el poder y la visión sobre la complejidad de la psique femenina y por eso las directoras tenemos que corregir las visiones de los directores sobre las mujeres".

Siempre interesada en la proyección de mujeres fuertes y valientes, Baccar realizó en 1995 Habiba M'Sika donde recupera la historia de una cantante y bailarina judía de los años 20 y 30. En 2006 realizó las ficciones La flor del olvido (2005) y El Jaida (2017). Luego de la revolución que inició la "primavera árabe» en su país en diciembre de 2010 y derrocó a Ben Ali tras 30 años de dictadura, Baccar fue convocada para la Asamblea Constituyente. Años después, se convirtió en la primera mujer en presidir un grupo parlamentario en Túnez desde donde continúa su incesante lucha por más y mejores derechos para las mujeres de su país.

La vecina Argelia tiene una historia turbulenta lo que sin dudas ha influido en la producción audiovisual y las posibilidades de las mujeres de participar en ella. Luego de más de un siglo de colonialismo francés y cinco largos años de guerra el país logró su independencia en 1962 de la mano del Frente de Liberación Nacional (FLN). Tras sucesivos golpes y una primavera socialista, en el que el FLN buscó ser punta de lanza del antiimperialismo en la región, el país se hundió en una severa crisis que decantó en el triunfo de la opción política islamista con el triunfo electoral del Frente Islámico de Salvación (FIS) en 1990, su posterior proscripción y el comienzo de la sangrienta guerra civil que duró hasta 2002. En este contexto, el cine argelino ha sido definido por sus revoluciones y guerras, construcciones normativas de la masculinidad y las historias masculinas.

Assia Djebar fue la primera en tomar la cámara y dirigir documentales en el país. Su primera profesión fue la de escritora y allí tomó este seudónimo, su nombre real 
era Fátima Zohra Imalayen. Su primer film, La Nubia de las mujeres del Monte Chenoua (1978) fue seguido de La Zerda, o los cantos del olvido (1982) y estos fueron los únicos que realizó, ambos ya residiendo en Francia, donde se estableció en 1966. La Nubia de las mujeres del Monte Chenoua reúne los relatos de un grupo de argelinas y su participación en la lucha de liberación nacional como apoyo de los combatientes. Se resalta la trasmisión de la historia oral y los cantos tradicionales; ambos patrimonio cultural femenino. Su segunda película retoma esta impronta aunque más en la línea militante del Tercer Cine en el plano de examinar el impacto de la colonización francesa y la construcción orientalista que ésta hizo sobre las mujeres locales.

La guerra civil dejó en pausa las producciones culturales, creó un clima de violencia total y produjo miles de víctimas fatales. Una de ellas fue la militante feminista Nabila Djahnine quien en 1995 es asesinada por los islamistas en Tzi Ouzou. En 2006 su hermana Habiba regresó de su exilio en Francia para filmar el documental Carta a mi hermana, recuperar la memoria de Nabila y tratar de comprender los años oscuros que aún se revelan cubiertos de dolor y silencios. Tras el fin del conflicto, algunas argelinas comenzaron también a trabajar el género documental, entre las que se destaca Bahia Bencheikh-El Fegoun. Su primera película, Nosotras afuera (2016), reflexiona sobre el papel de las mujeres en el espacio público, la libertad, el respeto y cuestiona la decisión de llevar el velo. La segunda, Fragmentos de sueños (2017), muestra las manifestaciones y revueltas ocurridas en el país con el impulso de la Primavera árabe y la represión del gobierno de Abdelaziz Bouteflika, uno de los dictadores árabes que quedó en pie tras las revueltas en la región.

Tampoco en Marruecos el ingreso de las mujeres en el mundo del cine fue temprano. A diferencia de Túnez y Argelia, Marruecos no contaba con un aparato mediático de propaganda como el instalado por Bourguiba y el FLN ni fue influido como sus vecinos por el movimiento del Tercer Cine. Farida Bourquia fue la primera en incursionar en el género documental para la televisión y en cine realizó mayormente ficciones dramáticas. En 1975 estuvo al frente una serie documental sobre las mujeres marroquíes para la televisión (Orlando, 2001, p. 144).

A partir de 1999, el país atravesó una transición profunda tras «los años de plomo» (1960-1999) del reinado de Hassan II y la coronación de su hijo Mohammed VI. Luego de décadas de asfixia social, numerosos sectores de la sociedad comenzaron a manifestarse con la expectativa de abrir el espectro público. En este contexto, cuantiosos films se ocuparon de la problemática de las mujeres marroquíes y su lucha contra las ataduras de una sociedad patriarcal tradicional.

La primera mujer que se dedicó exclusivamente al género documental fue Izza Génini. Luego de producir Transes (1981) dirigida por Ahmad al Maanouni dirigió Aita (1987) y continuó trabajando hasta 2007 cuando realizó su último film: Nubia de oro y de luz. Establecida en Paris desde 1960, esta cineasta se ha dedicado a recoger las tradiciones musicales de las diferentes regiones de Marruecos rescatando su diversidad cultural. Manifiesta en una entrevista:

Me gustan los documentales. Es un medio al que aprecio, ya que te permite descubrir cosas y personas de una manera muy física. No conocemos mucho sobre el patrimonio del África negra y del Magreb sobre los que se deberían hacer muchos documentales. No hay carencia de temas o de ideas. El documental es ante todo una escuela irremplazable (en Deffontaines, 1993, p. 15) 
Tomando una temática urgente que luego se volvió habitual en el género, Yasmine Kassari realizó el corto documental Cuando los hombres lloran (2002) sobre la inmigración clandestina a España. En sus siguientes trabajos desarrolló un estilo propio de docuficción, como en El niño dormido (2004) film que trabaja sobre la segregación de género, las conductas impuestas a las mujeres y recupera una figura de la creencia popular preislámica de que una mujer embarazada puede poner el feto «a dormir» a la espera de mejores tiempos para traerlo al mundo.

Retomando el tema de la inmigración y la crisis identitaria, en 2002 la periodista Leila Kilani rodó Tanger, el sueño de los incendiarios, donde muestra la vida de los jóvenes que se acercan a esa ciudad soñando emigrar a España e «incendiar» su identidad (Fabre, 2016). El año siguiente realizó Zad Moultaka y en 2008 Nuestros lugares probibidos donde sigue durante tres años el recorrido de cuatro familias en su búsqueda sobre la verdad de lo sucedido durante "los años de plomo» tras 40 años de silencio.

\section{Conclusiones}

El recorrido propuesto en las páginas precedentes habilita trazar algunas tendencias generales en relación a las documentalistas árabes. En principio, el hecho de que su número no cese de incrementar y supere a los hombres dedicados a esta profesión, es sin dudas un indicador que permite repensar la situación de las mujeres y los roles de género asignados. El cine se evidencia aquí como una plataforma de visibilidad a la vez que facilita la comunicación entre pares y audiencias del mundo, estableciendo interesantes intercambios que exceden lo meramente profesional.

A su vez, el reconocimiento mutuo, el tejido de redes y la colaboración entre cineastas se revela fundamental para el desarrollo de la producción audiovisual en una región caracterizada por gobiernos autoritarios y férreos aparatos de censura. Ligado a ello, una de las cuestiones más espinosas tiene que ver justamente con el hecho de que muchas de las realizadoras trabajen desde países europeos y sean por ello cuestionadas sus miradas y víctimas de sospechas en sus intenciones.

En lo relativo a las temáticas, se mantiene el interés sobre los relatos en primera persona de las mujeres, sus experiencias y problemáticas buscando dar cuenta de los diferentes contextos y realidades así como de recuperar la memoria histórica de sus luchas. La necesidad de asir la realidad y los sueños, de recuperar los paisajes y la esperanza y de dar vida en las peores circunstancias ha sido, y continúa siendo, una tarea urgente para estas mujeres.

\section{Bibliografía}

Abu Lughod, Lila (1998). Remaking Women. Feminism and Modernity in the Middle East. New Jersey: Princeton University Press.

Al Abdallah, Hala (2016). Entrevista en el Forum Transregionale Studien. Disponible en: https:// vimeo.com/138175053

Boughedir, Ferid (1987). Caméra Arabe. Película documental (75 min.) Paris.

Bracco, Carolina (2017). «La construcción femenina en los albores del cine egipcio». Revista Imagofagia, número 15, abril. Buenos Aires: Asociación Argentina de Estudios de Cine y Audiovisual (AsAECA). Disponible en: http://asaeca.org/imagofagia/index.php/imagofagia/ article/view/1245 
Charrad, Mounira (2001). States and Women's Rights. The Making of Postcolonial Tunisia, Algeria, and Morocco Londres: University of California Press.

Ghanayem, Muhammad Hamza (2000). «Before Birth, After Death». Gaaa, Vol. 3 (Invierno), pp. $12-17$.

Fabre, Clarisse (2012). «'étais une littéraire, je sacralisais l'écrit, mais pas l'image». Le Monde, 31 de enero de 2012. Disponible en: https://www.lemonde.fr/cinema/article/2012/01/31/leilakilani-j-etais-une-litteraire-je-sacralisais-l-ecrit-mais-pas-1-image_1636876_3476.html

Hennebelle, Guy y Khayati, Khemaïs (eds.) (1977). La Palestine et le Cinema. Paris: E.100

Hillauer, Rebecca (2005). Encyclopedia of Arab Women Filmmakers. El Cairo: American University Press.

Joseph, Suad (1991). «Elite Strategies for State-Building: Women, Family, Religion and State in Iraq and Lebanon" en: Kandiyoti Deniz (ed.) Women, Islam and the State. Philadelphia: Temple University Press.

Kandiyoti, Deniz (1991). Women, Islam and the State (Philadelphia: Temple University Press).

Masri, Mai (2018). Masterclass en el Festival Ciné-Palestine. Disponible en https://www.youtube. com/watch?v=jelu_u33k58

Mostafa, Dalia Said (2015). «Jocelyne Saab: A Lifetime Journey in Search of Freedom and Beauty» en Gugler, Josef (ed.) Ten Arab Filmmakers: Political Dissent and Social Critique. Bloomington: Indiana University Press.

Orlando, Valerie (2011). Screening Morocco. Contemporary Film in Changing Society. Ohio: Ohio University Press.

Ruiz-Almodóvar, Caridad (ed. y trad.) (2005). El derecho privado en los países árabes: traducción de los códigos de estatuto personal. Granada: Universidad de Granada-Fundación Euroárabe de Altos Estudios.

Samak, Qussai (1977). "The Politics of Egyptian Cinema». MERIP Reports 12-13.

Sela, Rona (2017). Looted and Hidden. Palestinian Archives in Israel. Película documental (46 min.) Tel Aviv.

Shafik Viola (1988). Arab cinema. History and cultural identity. El Cairo: AUC Press.

Thoraval, Yves (1988). Regards sur le cinéma égyptien1895-1975. París: Éditions L'Harmattan,

Van de Peer, Stefanie (2017). Negotiating Dissidence: The Pioneering Women of Arab Documentary. Edinburgo: Edinburgh University Press. 